ISSN 2236-0859

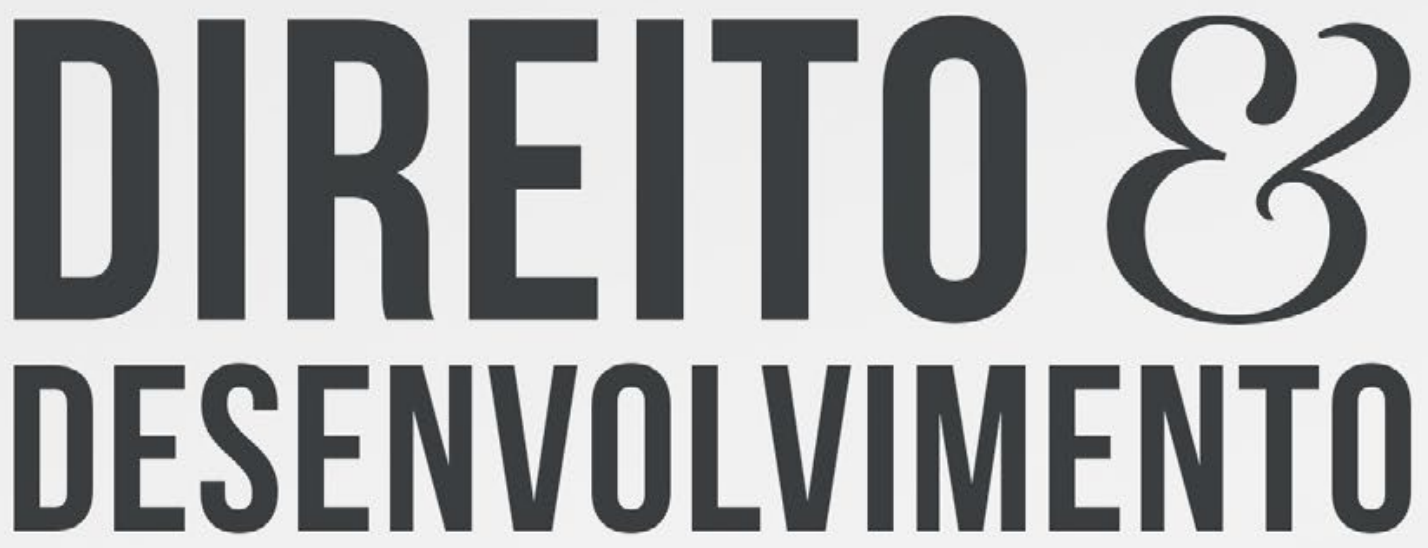

REVISTA DO PROGRAMA DE PÓS-GRADUAÇÃO EM DIREITO MESTRADO EM DIREITO E DESENVOLVIMENTO SUSTENTÁVEL

\title{
A ORDEM ECONÔMICA NO BRASLL: CONTRARIEDADES A DEFESA DO MEIO AMBIENTE
}

\author{
JACOPO PAFFARIN \\ ALEXANDRE MARQUES SILVEIRA
}




\section{A ORDEM ECONÔMICA NO BRASIL: CONTRARIEDADES A DEFESA DO MEIO AMBIENTE}

\section{THE ECONOMIC ORDER IN BRAZIL: CRITICISMS IN DEFENSE OF THE ENVIRONMENT}

Recebido: 02/05/2018

Aprovado: 20/12/2018

Jacopo Paffarini*
Alexandre Marques Silveira**

RESUMO: O presente estudo tem por objetivo analisar a compatibilidade da ordem econômica no Brasil com o princípio da defesa do meio ambiente que está presente no inciso $\mathrm{V}$ do artigo 170 da Constituição Federal de 1988. A pergunta que orientará a pesquisa proposta é: como a ordem econômica no Brasil atua sobre a defesa do meio ambiente. Como forma de responder a presente questão, se explorará os desdobramentos da ordem econômica e da crise ambiental a partir das contribuições do sociólogo de Ulrich Beck e por fim se fará um estudo crítico usando como aporte teórico a criminologia crítica e criminologia verde. Para tanto, o método a ser utilizado é o dedutivo que parte de observações gerais para chegar a um objetivo de pesquisa específico. Quanto ao método de procedimento este será o monográfico. Conclui-se que a partir de um estudo crítico, que os mecanismos da ordem econômica e de livre iniciativa no Brasil continuam sendo incompatíveis com a justiça social e a proteção do meio ambiente.

Palavras-chave: Dano social. Defesa do Meio-ambiente. Ordem Econômica. Riscos.

ABSTRACT: This study aims to analyze the compatibility of the economic order in Brazil with the principle of environmental protection declared at the article 170, V, of the Federal Constitution of 1988. The question that guided the proposed research is: how the economic order in Brazil acts in defense of the environment. In order to give an answer, the developments of both the economic order and the environmental crisis will be related to the contributions of the sociologist Ulrich Beck and, finally, a critical approach will be proposed by using the theoretical contribution of the critical criminology and the green criminology. Therefore, the method that has been used is deductive, which starts from general observations to reach a specific research goal. About the procedure followed, it will be mostly based on a monographic study. The conclusion, from a critical perspective, is that the mechanisms of the economic order and free initiative in Brazil continue to be incompatible with social justice and environmental protection.

Keywords: Social Harm. Environmental Protection. Economic Order. Risks.

\footnotetext{
*Doutor em Direito Público pela Università degli Studi di Perugia (Itália). Pos-Doutor em Direito - Faculdade Meridional (Brasil). Professor Permanente no Programa de Pós-Graduação Stricto Sensu em Direito, Faculdade Meridional - IMED. Bacharel em Direito pela Università degli Studi di Perugia. Membro pesquisador do Grupo Internacional de Pesquisa «Rights behind Bars in Europe» financiado pelo Ministério de Instrução, das Universidades e Pesquisa (Decreto Direttoriale, 25 giugno 2015 n. 1350). Colaborador assistente na Cátedra de Direito Constitucional e Direito Público Comparado, de titularidade do Prof. Dr. Maurizio Oliviero, junto ao Curso de Direito da Università degli Studi di Perugia. E-mail: jacov1983@gmail.com

** Mestre em Direito pela Faculdade Meridional de Passo Fundo (IMED), Linha de Pesquisa - II Mecanismos de Efetivação da Democracia e da Sustentabilidade - Área de concentração - Direito, Democracia e Sustentabilidade, onde foi bolsista PROSUP/ CAPES. Graduação em Direito pela Faculdade Metodista de Santa Maria (FAMES). E-mail: alexandremarquessilveira@gmail.com
} 


\section{INTRODUÇÃO}

Com base em estudos da criminologia, o capitalismo de mercado possui diversos mecanismos que resultam em danos massivos, tanto na espera social quanto ambiental. Privatizações são preconizadas como forma de progresso e prosperidade ao país, mascarando os altos valores embolsados pela espera privada. O conluio entre Estados e Mercados tem sido alvo do estudo da criminologia como forma de apurar crimes que não estão presentes na legislação penal.

Crimes de guerra, torturas, terrorismo, desocupações forçadas e tragédias ambientais são alguns dos danos que compõem a cifra oculta de Estados e Mercados. O presente estudo irá focar em um dos maiores danos causados por esse conluio. Os danos ambientais resultam em massivas vitimizações humanas e não humanas.

Há muito tempo o Brasil se desenvolveu por intermédio da exploração de seus recursos naturais. Atualmente após grandes catástrofes ambientais, as autoridades do país vêm se preocupando com a implementação de um desenvolvimento sustentável. A Constituição Federal de 1988 em seu artigo 170 ao tratar da ordem econômica no país, procurou coibir as práticas nocivas ao meio ambiente criando princípios norteadores da atividade econômica.

O princípio presente no inciso VI do referido artigo, trata da defesa do meio ambiente no Brasil, porém os demais princípios versam sobre propriedade privada, livre concorrência, soberania nacional e outros princípios que estão totalmente ligados ao liberalismo e ou neoliberalismo. Dessa forma, o problema que norteia o presente estudo é: como a ordem econômica no Brasil atua sobre a defesa do meio ambiente?

O primeiro capítulo tratará da ordem econômica no país e seus desdobramentos. O segundo capítulo tratará sobre a crise ambiental a partir da perspectiva de Ulrich Beck, sociólogo muito utilizado por autores e autoras da criminologia para investigar os riscos da sociedade moderna, especialmente no que tange danos ao meio ambiente. O terceiro e último capítulo versará sobre a ordem econômica e os riscos de danos sociais corporativos, utilizando como marco teórico a criminologia crítica e criminologia verde como forma de fazer um estudo critico na área do direito para que se possam ter conclusões a partir dos argumentos expostos, afastando-se de um estudo meramente dogmático.

Para tanto, o método de abordagem que servirá de referência para análise das ideias, informações e resultados desta pesquisa é o método dedutivo que parte de observações gerais para chegar a um objetivo de pesquisa especifico. Quanto ao método de procedimento este será o monográfico, de modo que serão usados vários doutrinadores para que haja embasamento para o tema defendido no trabalho.

\section{ORDEM ECONÔMICA NO BRASIL E SEUS DESDOBRAMENTOS}

No final da década de 70, muitos países da Amarica Latina passavam por uma grande crise econômica e social devido as antigas técnicas desenvolvimentistas praticadas pelos Estados (CARNEIRO, 2012, p.15). Uma das saídas para crise idealizada na época, foi o apoio e a atuação da classe empresarial, que instaurou a discussão sobre a necessidade de uma economia de mercado efetiva, "[...] o discurso liberal radical, combinado com a abertura da economia e o processo de privatizações inaugura o que poderíamos chamar da 'Era Liberal' no Brasil" (FILGUEIRAS, 200o, p.84).

Esse processo, que culminou com a afirmação do projeto político neoliberal ea construção de um novo modelo econômico, redefiniu as relações políticas entre as classes e frações 
de classes que constituíam a sociedade brasileira. A vitória desse projeto expressou, ao mesmo tempo em que estimulou, um processo de transnacionalização dos grandes grupos econômicos nacionais e seu fortalecimento no interior do bloco dominante, além de exprimir, também, a fragilidade financeira do Estado e a subordinação crescente da economia brasileira aos fluxos internacionais de capitais (FILGUEIRAS, 2006, p. 183).

O liberalismo decorre do individualismo, e tem como fundamento a garantia da propriedade privada, já o neoliberalismo para muitos autores seria uma forma avançada do próprio liberalismo (O’MALLEY, 2017, p. 38). O termo neoliberalismo torna-se significativo durante a década de 70 em um contexto onde acontecia a privatização de empresas estatais e a globalização dos mercados (DRAIBE,1993). A ascendência do neoliberalismo também trouxe outros reflexos:

\begin{abstract}
A defesa do mercado como modelo para a maior parte da ordem social (incluída a maioria das operações estatais sobreviventes), defesa dos empreendimentos comerciais como modelo para a atividade individual e organizacional, e idealização do empresário como o paradigma de autogovernança individual; A promoção de relações de profissionalismo, especificamente a formação de relações contratuais ou quase contratuais, como “parceiras” entre agências estatais e não-estatais (O’MALLEY, 2017,p. 136).
\end{abstract}

Com a promulgação da Constituição Federal de 1988, as questões de ordem econômica se concretizaram através do disposto no artigo 170: "a ordem econômica, fundada na valorização do trabalho humano e na livre iniciativa, tem por fim assegurar a todos existência digna, conforme os ditames da justiça social" (BRASIL, 1988). O artigo ainda traz um rol de princípios em seus incisos como, por exemplo, soberania nacional e livre concorrência. Mas para esse trabalho o princípio mais importante a ser mencionado é o do inciso VI, que trata sobre a defesa do meio ambiente e dos impactos ambientais.

A livre iniciativa e o trabalho humano visam garantir a todos uma existência digna, o direito econômico deve respeitar os princípios basilares da Constituição Federal de 1988, sob pena de cometer um ilícito e sofrer sanções penais e administrativas (COMPARATO,1989, p.39). Os meios utilizados para alcançar as grandes metas do desenvolvimento econômico a muito tempo tem prejudicado o meio ambiente, "[...] a sobrevivência do business, dos lucros e dos privilégios é mais importante do que a sobrevivência do planeta ou, em todo caso, da maioria da sua população" (LATOUCHE, 2012, p.45).

Nesse mesmo sentido Eros Grau afirma que:

Não pode haver promoção do bem de todos ou da justiça social sem o respeito da dignidade da pessoa humana, o que não se dá sem o reconhecimento da função social da propriedade e sem que a utilização dos recursos do ambiente seja sustentável (GRAU, 1999, p. 2018).

Deve-se reconhecer a importância do desenvolvimento econômico de uma sociedade, mas no Brasil, as diversas influencias exercidas sobre a ordem econômica, fazem com que todo esse desenvolvimento seja dependente de estruturas corporativas criando monopólios (BOLAÑO, 1996). De acordo com Carneiro, o neoliberalismo no Brasil deixou passar a oportunidade de privatizar os grupos nacionais, o que poderia criar uma maior competitividade no mercado mundial e um fortalecimento da moeda brasileira (CARNEIRO, 2002, p.21).

Esse fato contribui para que corporações multinacionais continuem tendo o domínio do mercado e da economia, "[...] Num mundo globalizado, são as grandes empresas internacionais que ditam as regras de sobrevivência” (PERIN,2003, p. 146). Com a globalização as estratégias das grandes corporações são: "ocupar os mercados de periferia adquirindo empresas já 
existentes para ajustar as metas e linhas de produção e uma estratégia global formada fora do país" (CARDEIRO, 2002, p. 22).

Em nome da livre iniciativa privada promove-se uma forma descontrolada de concorrência, com a criação de modelos de autonomia contratual e de governança empresarial emprestadas pelas grandes corporações. Trata-se de um processo de padronização do ato negocial, que reduz a margem de autonomia do consumidor/usuário, assim como a capacidade do pequeno e médio produtor, isto é, a base tradicional da economia nacional. Os Estados cujas classes políticas não entenderam a carga desestabilizadora deste processo - como no caso brasileiro - estão vivenciando uma crise do modelo democrático, devido a desconfiança da população sobre a capacidade dos tradicionais órgãos representativos de lidar com a crise. No enquanto, a necessidade de manutenção dos investimentos estrangeiros no território nacional, ainda mais à luz da necessidade de recuperação da dívida pública, aumenta a "alavanca negocial" das corporações (PAFFARINI, 2017):

As shown by some comparative studies, the principle of private autonomy has been boosted as a common standard for the global market regulation. There is no field of international investments where corporation have not insisted on regulating their activities in the host State, as well as any dispute arising from. At the same time, even acknowledging this great pressure by the industrial and financial élite, the distinction between "economic (self)regulation" and "governance" is still crucial in order to implement human rights and sustainable growth in Brazil (PAFFARINI, 2017, p. 38)..

Diante das mudanças da era globalizada e modificações das estratégias de mercado, a criminologia passou a preocupar-se com os riscos ${ }^{3}$ dos monopólios corporativistas (CSOHNGEN et $\mathrm{al}$, 2017). O próximo capítulo tratara sobre os riscos ocasionados pelo capitalismo global e seus desdobramentos a partir da ótica da criminologia verde.

\section{CRISEAMBIENTAL:OSRISCOS AOMEIO AMBIENTE APARTIRDA PERSPECTIVA DE ULRICH BECK}

Com as conquistas ocidentais, muitas foram às catástrofes, conflitos sociais e proliferação de doenças. A partir de um estudo social e cultural, o conceito de Sociedade de Risco de Beck está atrelado a uma fase da modernidade onde esses conflitos e riscos tornamse frequentes (BECK, 1997). Nessa perspectiva, ao tratar da noção complexa de uma era de riscos Beck afirma que "[...] aí reside à novidade de sua força cultural e política. Sua violência é a violência do perigo, que suprime todas as zonas de proteção e todas as diferenciações da modernidade" (BECK, 2010, p. 7).

Nas sociedades de risco, o mais importante é o capital, a dominação social, estrutural e econômica, a partir disso "[...] emerge um novo tipo de destino 'adscrito' em função do perigo, no qual nenhum esforço permite escapar" (BECK, 2010, p. 8). A Modernidade desenvolvida com o fundamento de trazer melhores condições para vida das pessoas é causadora de grandes reflexos na humanidade, em especial na esfera ambiental, pois a criação de bombas radioativas, perigos da era nuclear e toxinas que poluem o ar, água e todo meio ambiente, ameaçam a sobrevivência de todos os seres vivos do Planeta Terra.

Assim como Beck, outros autores também verificam as questões de modernização, industrialização e desenvolvimento descontrolado como formas de risco ou ameaça a sociedade.

3 Aqui o conceito de risco é aquele usado por Ulrich Beck em sua obra Sociedade de Risco. De acordo com o autor, na sociedade de risco o mais importante é o capital, a dominação social, estrutural e econômica. BECK, Ulrich. Sociedade de risco: rumo à outra modernidade. Tradução de Sebastião Nascimento. São Paulo: Editora 34, 2010. 
O economista e filosofo francês Latouche, em sua obra "O Desafio do Decrescimento", também segue essa perspectiva, certificando que "[...] é incontestável que tem aumentado de maneira notável, mas ao mesmo tempo a perpetuação do crescimento louco provoca uma degradação global" (LATOUCHE, 2012, p. 42).

Nesse sentido, a concepção de risco para Beck também está ligada aos processos de globalização e seus efeitos, os quais influenciam diretamente na harmonização do planeta e na sustentabilidade social (BECK, 1999).

O reverso da natureza socializada é a socialização dos danos à natureza, sua transformação em ameaças sociais, econômicas e políticas sistemáticas da sociedade mundial altamente industrializada. Na globalidade da contaminação e nas cadeias mundiais de alimentos e produtos, as ameaças à vida na cultura industrial passam por metamorfoses sociais do perigo: regras da vida cotidiana são viradas de cabeça para baixo. Mercados colapsam. Prevalece a carência em meio à abundância. [...] E tudo isso sem que a sustentabilidade das pessoas tenha qualquer coisa que ver com suas ações, ou suas ofensas com suas realizações, e ao mesmo tempo em que a realidade segue inalterada diante dos nossos sentidos (BECK, 2010, p.10).

Ademais, com a globalização da modernidade (GIDDENS, 1991, p. 6o) importações, exportações e a alta industrialização mundial os riscos tornaram-se ainda maiores, tendo em vista as contaminações das redes mundiais de alimentos e de produtos industrializados, o mundo passa pela "[...] metamorfose social do perigo" (BECK, 2010, p.10). Beck assevera que na Sociedade de Risco, as ameaças alcançam a todos de uma maneira em que não existe mais distinção de classes sociais, uma vez que as inseguranças produzidas pelas ameaças financeiras, terroristas, ecológicas, internacionais e bioquímicas são suscetíveis a todos.

Todos esses atos têm efeitos em longo prazo, prejudicando a sustentabilidade social, visto que com a desenfreada degradação do Meio Ambiente, não permite que as matériasprimas se regenerem. Essa situação causa um efeito em cadeia que prejudica todos os seres vivos, inclusive o próprio ser humano. No mesmo ensejo, Latouche, ao explanar sobre a modernização e o desenvolvimento desenfreado afirma que "[...] a insuficiência dos recursos naturais e os limites da capacidade de regeneração da biosfera nos condenam a pôr em causa o nosso modo de vida" (LATOUCHE, 2012, p. 121). Nessa linha de pensamento, Beck, ao discorrer sobre a globalização da modernização, inovações tecnológicas, desenvolvimentos acelerados e produtores de um cenário de riscos, assegura que:

A terra se transformou num assento ejetável, que não mais reconhece diferenças entre pobre e rico, branco e preto, sul e norte, leste e oeste. O efeito, porém só existe quando existir, e então ele não mais existirá. Essa ameaça apocalíptica não deixa, portanto, quaisquer rastros palpáveis na imediatez de sua ameaça (BECK, 2010, p. 44).

Dessa forma, as relações no mundo humano são marcadas por violência e desrespeitos, haja vista as desigualdades em determinadas regiões e a abundância de vidas cheias de luxos e em outras. A miséria e carência de alimentos básicos para uma vida saudável também influencia diretamente na esfera ambiental, pois o "[...] discurso sobre a sociedade mundial do risco pode nos fazer sobrevalorizar a relativa autonomia da crise ecológica e transformá-la numa perspectiva unidimensional da sociedade global" (BECK, 1999, p. 83).

Nas sociedades de risco os governos têm más administrações, onde a corrupção prevalece, onde há a má distribuição das riquezas que ocasionam uma produção social de riscos e insustentabilidade social, afetando diretamente os direitos e garantias, as quais o Estado deveria proporcionar. A "modernização desencadeada não apenas superou a suposição de uma 
natureza contraposta à sociedade, como também fez desmoronar o sistema intrassocial de coordenadas da sociedade" (BECK, 2010, p. 107). Nessa ótica Beck ainda assevera que:

[...] os chamados riscos globais abalam as sólidas colunas dos cálculos de segurança: os danos já não têm limitação no espaço e no tempo - eles são globais e duradouros; não podem mais ser atribuídos a certas autoridades - o princípio da causação perdeu a sua eficácia; não podem mais ser compensados financeiramente - é inútil querer se garantir contra os efeitos de um worst case da ameaça em espira (BECK,1999, p.83).

O progresso da modernização ocasiona uma grande alteração na racionalização das pessoas, o que modifica muitos sentidos sociais, como a forma e o jeito de viver, a troca dos serviços manuais por máquinas, reconfigurando toda a organização da vida (BECK, 1999, p. 79-83). Os riscos acabam sendo a marca da sociedade moderna e industrializada, que por intermédio das ações dos indivíduos globaliza ameaças à vida na Terra.

As ações reiteradas de desmatamentos acúmulos de lixo tóxico e liberação de gases poluentes colocam em sofrimento a vida na Terra, "[...] os riscos da modernização são o arranjo conceitual, o enquadramento categorial no qual violações e destruições da natureza inerentes a civilização são socialmente concebidas" (BECK, 2010, p. 99). Não obstante, num segundo momento de sua obra "Sociedade de Risco", o citado autor pontua sobre a individualização na constituição social, o conceito aborda o sujeito como elemento central das ações no mundo. Ao ilustrar esse tema, Westphal esclarece que:

\footnotetext{
A individualização é tema da análise sociológica contemporânea e Ulrich Beck analisa esse processo no contexto de mudanças da primeira para a segunda modernidade. $\mathrm{Na}$ modernização reflexiva, marcada por riscos, há transformações relacionadas ao mundo do trabalho, à família, à política e ao lugar e papel do indivíduo na sociedade, ocorrendo a reflexividade da modernidade sobre ela mesma (WESTPHAL, 2010, p. 419).
}

Nesse ponto, Beck elucida que o alto nível de controle e responsabilidade dos indivíduos em relação às ameaças e exposição aos perigos, onde estes seriam os produtores e gestores das grandes cargas de riscos. Ao fazer essa colocação em sua obra, Beck não específica quais indivíduos são responsáveis pelos riscos, pois a qualidade de individuo é muito ampla, o que de certa forma, acaba originando a chamada irresponsabilidade organizada (LEITE et al, 2002, p. 20), o que também alcança uma desreponsabilização dos verdadeiros culpados pelos "riscos" e uma macrocriminalização de caráter preventivo (BUDÓ, 2014).

No entanto, apesar das grandes contribuições de Beck para o entendimento da insustentabilidade da sociedade atual, deve-se ter o cuidado para que não nos tornemos meros guardiões do controle social imposto pela lei (BERNAL et al, 2014, p. 63). Por detrás da sociedade capitalista despontam crimes ambientais, insustentabilidade social e também interesses não declarados. Para isso, se fará um estudo a partir da criminologia crítica e criminologia verde no próximo capítulo para que se possa esmiuçar a problemática no presente trabalho.

\section{A ORDEM ECONÔMICA E OS RISCOS DE DANOS SOCIAIS CORPORATIVOS}

Os desdobramentos dos sistemas de governos do país (liberalismos e ou neoliberalismo) tornaram o desenvolvimento econômico dependente de grandes corporações (BOLAÑO, 1996). A criminologia crítica, ao colocar o dano social como seu objeto de análise, verifica que esses mecanismos podem causar danos sociais massivos (BERNAL et al, 2014, p. 35- 68).

Por esse motivo, "[...] ultrapassar o conceito de crime para o de dano social permite à criminologia compreender o impacto de ações que não alcançam a definição de proibidas, 
ilegais ou criminosas" (BUDÓ, 2016, p.130), o que garante uma maior visibilidade da vitimização, bem como o reconhecimento de danos sociais não abrangidos pelo controle social formal. Ao consolidar essa perspectiva, Budó, ao tratar sobre a abrangência do conceito de dano social, sustenta que:

[...] ao colocar o dano social no centro dos objetos de análise, denunciam-se as próprias organizações políticas e econômicas vigentes, nas esferas local, nacional e global, sem cuja superação não é possível imaginar mudanças no insustentável desenvolvimento do capital e em todas as vitimizações que o acompanham (BUDÓ, 2015, p. 259).

E é nesse ensejo que entra a problemática do presente trabalho. A ordem econômica e a sua compatibilidade com o princípio da defesa do meio ambiente, dispostos no artigo 170 da Constituição Federal de 1988. A partir dos estudos criminologia verde verifica-se que: "danos simbióticos de Estado e agências corporativas que exploram danos ambientais (como, por exemplo, a violência do Estado e grupos de oposição, resíduos perigosos ao meio ambiente)", (WALTERS, 2017, p. 203). Dentro da área criminológica, os estudos sobre esses processos e dos danos vieram da sociologia, teóricos da área ambiental e políticas de vertentes verdes (WALTERS, 2017, p. 204).

Nessa perspectiva, surge a green criminology, impulsionada pelos estudos de Michale Lynch e Nigel South (WHITE; HECKENBERG, 2014). A criminologia verde tutela uma gama de questões ligadas ao meio ambiente, trazendo três tendências como base de investigação a justiça ambiental, a justiça ecológica e a justiça das espécies (WHITE, 2008). Além disso, a criminologia verde denuncia abusos e "atos que resultam em destruição ambiental, vitimização humana e não humana” (WALTERS, 2017, p. 205), resultantes de abusos do Estado e do poder corporativo.

De acordo com a teoria do risco, o capitalismo desenfreado e a busca incessante pelo desenvolvimento visam como prioridade o lucro, fazendo com que isso se sobreponha a todos os valores humanos, a democracia e também a proteção ambiental (BECK, 2010, p. 107). Os "Estados e corporações induziram atos de dano ambiental que motivaram as políticas e movimentos sociais verdes, bem como a evolução criminológica intelectual de ambos os lados do Atlântico" (WALTERS, 2017, p. 205).

Nesse sentido, alguns criminólogos lançaram mão da teoria do risco de Beck para interpretar os riscos e danos da sociedade moderna, "[...] embora o aumento do risco possa ser de enorme importância, talvez os criminólogos estejam mais preocupados com formas de emprego de risco" (O’MALLEY, 2017, p. 135). A concepção de risco para Beck está ligada aos processos de globalização e seus efeitos, os quais influenciam diretamente na harmonização do planeta e na sustentabilidade social (BECK, 1999).

É bem verdade que a sociedade está marcada pelo processo de globalização, pelos crescentes avanços tecnológicos, pelo consumismo e pelo ritmo ditado pelo neoliberalismo. A vida humana, incluída nos cálculos e estratégias políticas da modernidade, exige o máximo de aproveitamento econômico e estatístico. Contudo, a conscientização de estabelecer limites alçou o meio ambiente ao status de bem jurídico. Com isso, a legislação ficou mais rígida no que se refere à responsabilidade por manter um meio ambiente saudável e equilibrado e às sanções civis e administrativas para os transgressores.(PAFFARINI et al, 2017, p. 63).

Nesse seguimento, torna-se pertinente contestar a compatibilidade dos desdobramentos da ordem econômica no Brasil e o princípio da defesa do meio ambiente que se encontra no artigo 170 da Constituição Federal de 1988. Sobre essa problemática Derani expõem que: 
[...] não se trata de um relacionamento em sua origem conflitante, mas apenas dois aspectos da relação entre homem-natureza, frente a imanente necessidade de expansão produtiva da atividade econômica, que se torna apropriativa, onde a natureza passa a ser exclusivamente recurso (DERANI,2001, p. 191).

De acordo com Beck, a disseminação de riscos são fontes da crise ecológica mundial e comprometem os princípios naturais e os fatores econômicos do cultivo (BECK, 2010). Nesse sentido, a exaltação do consumo material tem raízes ideológicas profundas, que vão muito além da economia e da política, é preciso outro olhar sobre os danos sociais para que se possa ver o que fica invisível em meio aos interesses não declarados no mundo globalizado (BERNAL et al, 2014, p. 35-68).

\section{CONCLUSÃO}

A criminalidade de rua é facilmente reconhecida: homicídios, roubos, extorsões, latrocínios entre outros. Porém, danos massivos ocasionados por Estados e grandes corporações ficam invisibilizados por negações e desculpas desses agentes.

A criminologia crítica e a criminologia verde surgem como dois aportes teóricos de resistência, dando visibilidade as vitimizações humanas e não humanas ocasionadas pelo conluio de Estados e corporações. Esses marcos teóricos analisam de forma crítica as ações e políticas dos governos e dos mercados, sendo um dos grandes objetivos a busca por justiça social expondo e identificando problemas sociais e ambientais.

Nessa perspectiva, o presente estudo buscou responder o questionamento sobre a atuação da ordem econômica do Brasil sobre a defesa do meio ambiente. Para isso, no primeiro capítulo buscou-se demonstrar os desdobramentos da ordem econômica no país. Já no segundo capítulo discutiu-se sobre a crise ambiental e os riscos ocasionados pela sociedade moderna a partir dos apontamentos do sociólogo Ulrich Beck. E no terceiro e último capítulo, procurouse fazer um estudo crítico usando contribuições da criminologia crítica e criminologia verde como forma de ultrapassar os discursos convencionais sobre crime.

Contudo, vale salientar concluindo que apesar da Constituição Federal de 1988 trazer em seu artigo 170 regulamentação sobre as atividades econômicas no país e também o princípio da proteção do meio ambiente. A partir de um estudo crítico percebesse que os mecanismos da ordem econômica e de livre iniciativa no país continuam sendo incompatíveis com a justiça social e a proteção do meio ambiente.

Conforme demonstrado às atividades econômicas desenfreadas sempre oferecerão riscos ao equilíbrio social e ambiental. Dessa forma, cabe repensar como os seres humanos estão se relacionando com o meio ambiente, bem como refletir e regulamentar quais seriam formas de explorações aceitáveis, para que houvesse tempo do meio ambiente se regenerar.

\section{REFERÊNCIAS}

BECK, Ulrich. Modernização reflexiva: política, tradição e estética na ordem social moderna. São Paulo: Editora da Universidade Estadual Paulista, 1997.

Sociedade de risco: rumo a outra modernidade. Tradução de Sebastião Nascimento. São Paulo: Editora 34, 2010. 
BERNAL, Camilo Ernesto; CABEZAS, Sebastián; FORERO, Alejandro; RIVERA, Iñaki; VIDAL, Iván. Un debate epistemológico sobre el daño social, los crímenes internacionales y los delitos de los mercados. In: RIVERA, Iñaki (Coord..). Delitos de los Estados, de los Mercados y daño social. Barcelona: Anthropos, 2014.

BOLAÑO, César Ricardo Siqueira. Economia política, globalização e comunicação. Revista Novos Rumos, n. 25 (11). Disponível em: <http://www.bjis.unesp.br/revistas/index.php/ novosrumos/article/view/2047>. Acesso em: 13 dez. 2017.

BRASIL. Constituição (1988). Constituição da República Federativa do Brasil. Brasília, DF: Senado Federal, 1988.

BUDÓ, Marília de Nardin. Criminologia e dano social: a efetivação da sustentabilidade para além do direito penal. In: André Karam Trindade; Angela Araujo da Silveira Espindola; Salete Oro Boff. (Org.). Direito, democracia, sustentabilidade: Anuário do Programa de PósGraduação Stricto Sensu em Direito, Democracia e Sustentabilidade. 1, ed. Passo Fundo: IMED, 2014 .

Danos silenciados: a banalidade do mal no discurso científico sobre o amianto. Revista Brasileira de Direito, 127-140, jan.-jun. 2016. p. 130. Disponível em: <https://seer.imed.edu.br/ index.php/revistadedireito/article/view/1281>. Acesso em: 28 de dez. 2017.

CARNEIRO, Ricardo. Desenvolvimento em crise: a economia brasileira no último quarto do século XX. São Paulo: Editora UNESP, IE - UNICAMP, 2002.

COMPARATO, Fábio Konder. Para viver a democracia. São Paulo: Brasiliense, 1989.

CSOHNGEN, Clarice Beatriz; AMARAL, Augusto Jobim do; GLOECKNER, Ricardo Jacobsen. (Orgs). Criminologia e Governabilidade: Pat O’Malley. Florianópolis: Empório do direito. 2017.

DERANI, Cristiane. Direito ambiental econômico. São Paulo: Max Limonad, 2001.

DRAIBE, Sônia. As políticas sociais e o neoliberalismo: reflexões suscitadas pelas experiências latino-americanas. Revistausp, n. 17 (1993). Disponível em: < http://www.revistas.usp.br/ revusp/article/view/25959/27690>. Acesso em: 10 dez. 2017.

FILGUEIRAS, Luiz. A história do Plano Real: fundamentos, impactos e contradições. São Paulo: Boitempo, 200o.

O neoliberalismo no Brasil: estrutura, dinâmica e ajuste do modelo econômico. In: BASUALDO, Eduardo M; ARCEO, Enrique. (Orgs). Neoliberalismo y sectores dominantes: tendencias globales y experiencias nacionales. Buenos Aires: Consejo Latinoamericano de Ciencias Sociales. 2006.

GRAU, Eros Roberto. A ordem econômica na Constituição de 1988: interpretação e crítica. São Paulo: Malheiros, 1997. 
LATOUCHE, Serge. O desafio do decrescimento. Tradução de António Viegas. Lisboa: Instituto Piaget, 2012.

LEITE, José Rubens Morato; AYALA, Patryck de Araújo. Direito Ambiental na Sociedade de Risco. São Paulo: Forense, 2002.

O’MALLEY, Pat. Genealogia, sistematização e resistência no liberalismo avançado. In: CSOHNGEN, Clarice Beatriz; AMARAL, Augusto Jobim do; GLOECKNER, Ricardo Jacobsen. (Orgs). Criminologia e Governabilidade: Pat O’Malley. Florianópolis: Empório do direito. 2017.

Neoliberalismo e risco na criminologia. In: CSOHNGEN, Clarice Beatriz; AMARAL, Augusto Jobim do; GLOECKNER, Ricardo Jacobsen. (Orgs). Criminologia e Governabilidade: Pat O’Malley. Florianópolis: Empório do direito. 2017.

PAFFARINI, Jacopo. A Brazilian Outlook on the (Un) Sustainable Development of Corporate Capitalism. Revista Jurídica - Unicuritiba, vol.3, 2017. . Disponível em: <http://revista. unicuritiba.edu.br/index.php/RevJur/article/view/2167>. Acesso em 16 mar. 2018.

PAFFARINI, Jacopo; COLOGNESE, Mariângela Matarazzo Fanfa; HAMEL, Eduardo Henrique. A insuficiência da responsabilidade socioambiental empresarial na perspectiva do desenvolvimento sustentável. Direito e Desenvolvimento, João Pessoa, v. 8, n. 2, p. 5575. Disponível em: < https://periodicos.unipe.br/index.php/direitoedesenvolvimento/article/ view/541>. Acesso em: 02 mar. 2018.

PERIN, Jair José. A intervenção do Estado no domínio econômico e a função das agências de regulamentação no atual contexto brasileiro. Revista de Informação Legislativa, Brasília a. 40 n. 159 jul./set. 2003. Disponível em: < http://www2.senado.leg.br/bdsf/bitstream/handle/ id/496891/RIL159.pdf?sequence $=1 \#$ page $=138>$. Acesso em: 13 dez. 2017.

WALTERS, Reece. Criminologias verdes. In: CARLEN, Pat; FRANÇA, Leandro Ayres (Orgs.). Criminologias alternativas. Porto Alegre: Ciências Criminais, 2017.

WESTPHAL, Vera Herweg. A Individualização em Ulrich Beck: análise da sociedade contemporânea. Revista Emancipação, Ponta Grossa, v.10. pp. 419-433, 2010.

WHITE, Rob. Crimes Against Nature: Environmental Criminology and Ecological Justice. Cullompton: Willan Publishing, 2008.

WHITE, Rob; HECKENBERG, Diane. Green Criminology - An introdution to the study of environmental harm. New York: Routledge, 2014. 